\title{
A Magneto-Optical Nanoplatform for Multimodality Imaging of Tumors in Mice
}

Guosheng Song ${ }^{\dagger \S}$, Xianchuang Zheng $\$$, Youjuan Wang ${ }^{\dagger}$, Xin Xia ${ }^{\dagger}$, Steven Chu ${ }^{\ddagger}$, Jianghong Rao ${ }^{\S *}$

†State Key Laboratory of Chemo/Biosensing and Chemometrics, College of Chemistry and Chemical Engineering, Hunan University, Changsha, Hunan 410082, China.

$\S$ Molecular Imaging Program at Stanford, Department of Radiology, Stanford University School of Medicine, 1201 Welch Road, Stanford, California, 94305-5484, USA

$¥$ Departments of Physics and Molecular \& Cellular Physiology, Stanford University, Stanford, California 94305, USA.

* Correspondence and requests for materials should be addressed to J. Rao. E-mail: jrao@stanford.edu 

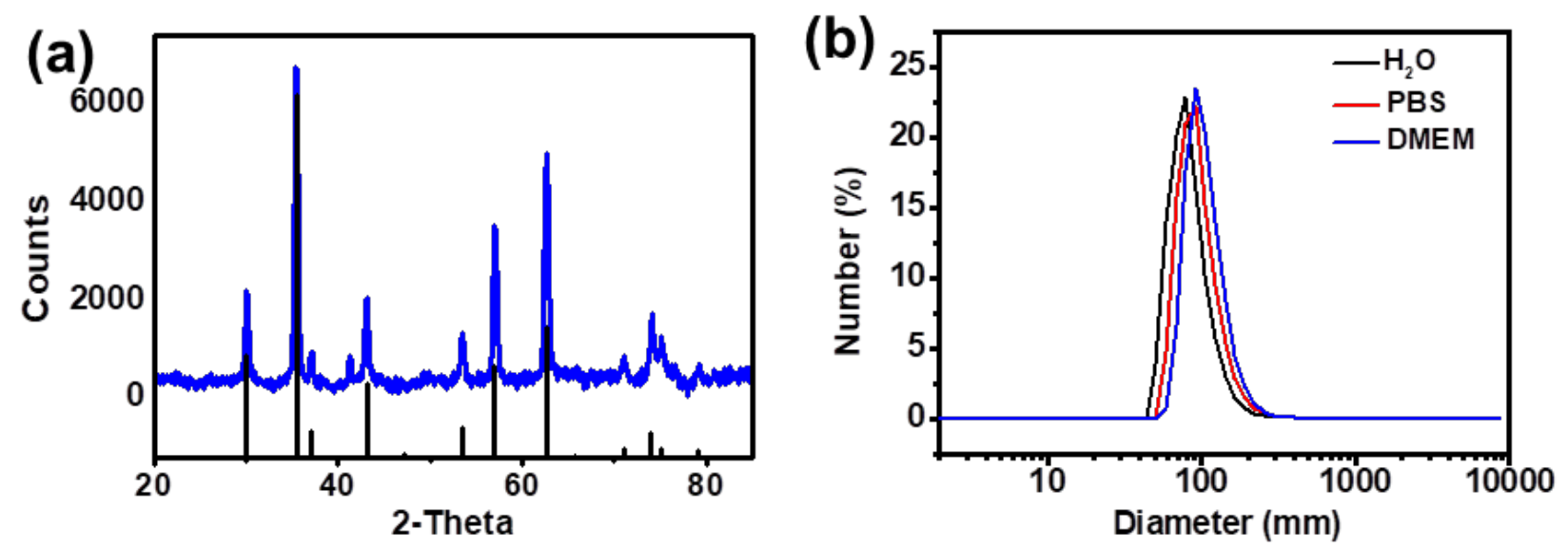

Figure S1. Characterization of MMPF NPs. (a) Powder XRD patterns of as-prepared iron oxide nanoparticles. (b) Hydrodynamic diameter of MMPF NPs in $\mathrm{H}_{2} \mathrm{O}$, PBS, and DMEM.
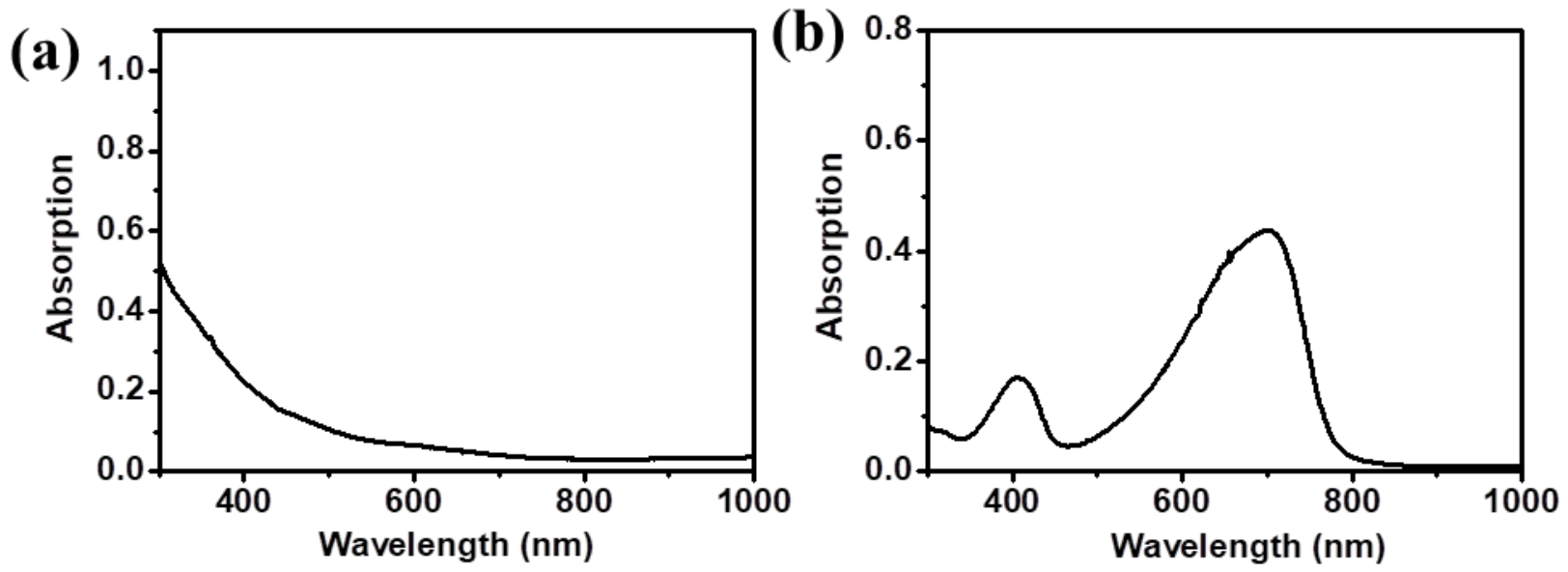

Figure S2. UV-Vis absorption spectra of (a) $\mathrm{Fe}_{3} \mathrm{O}_{4}$ nanoparticles and (b) semiconducting polymer. 


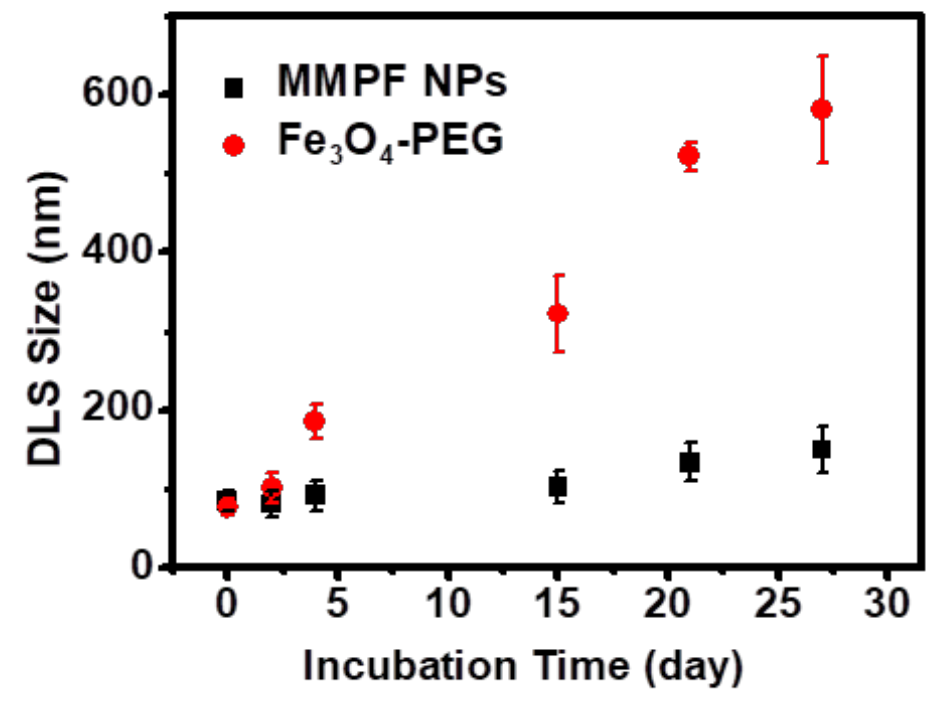

Figure S3. Hydrodynamic diameter of MMPF NPs and $\mathrm{Fe}_{3} \mathrm{O}_{4}-\mathrm{PEG}$ incubated in $\mathrm{PBS}$ at room temperature for various lengths of time.

(a)

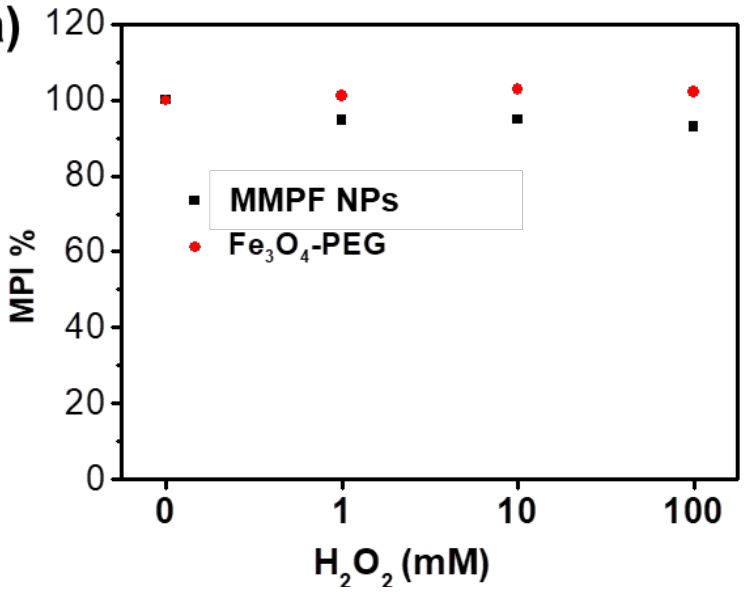

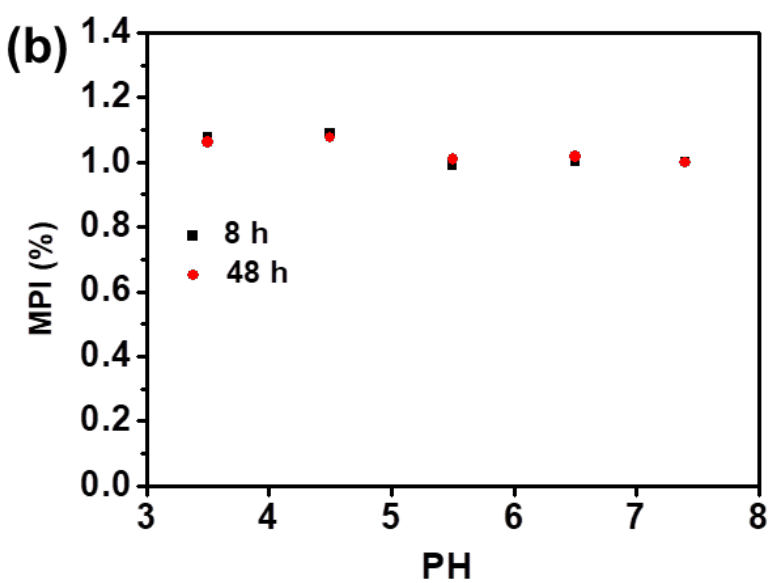

Figure S4. (a) The MPI signal stability of MMPF NPs and $\mathrm{Fe}_{3} \mathrm{O}_{4}-\mathrm{PEG}$ incubated with various concentrations of $\mathrm{H}_{2} \mathrm{O}_{2}$ for 24 h. (b) MPI signal of MMPF NPs incubated for 8 or $48 \mathrm{~h}$ in different $\mathrm{pH}$ buffer solutions. 


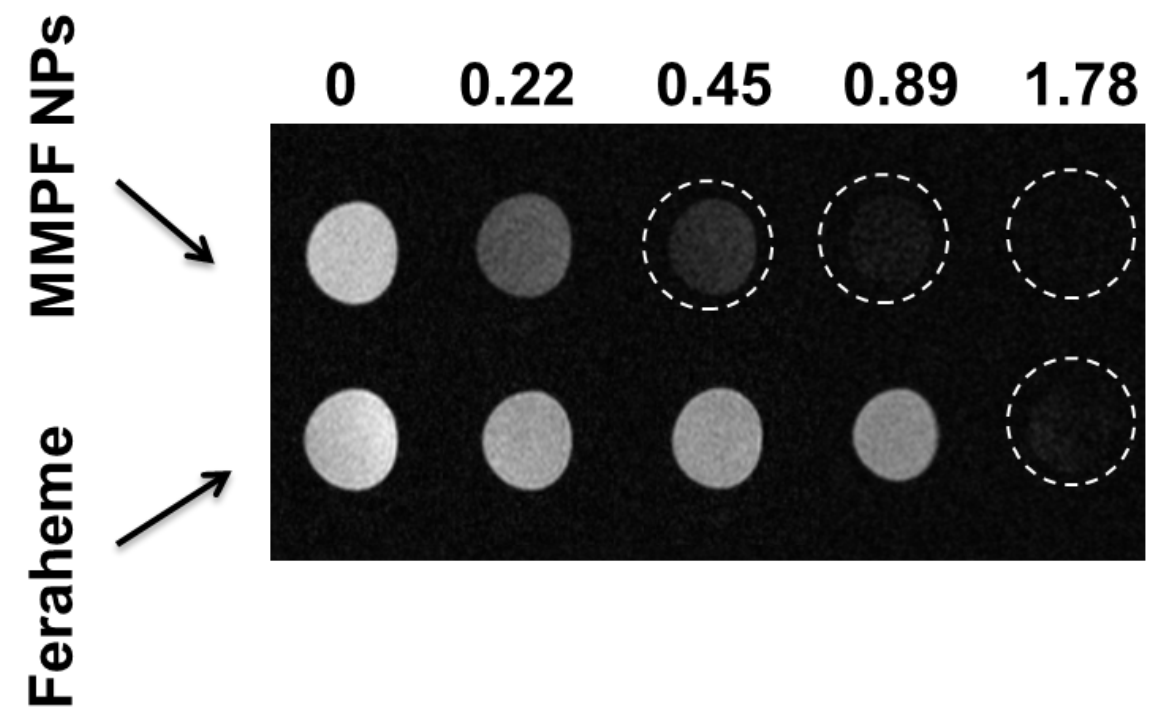

Figure S5. $\mathrm{T}_{2}$-MRI image of Feraheme and MMPF NPs solutions measured as the function of Fe concentration (e.g. 0, 0.22, $0.45,0.89,1.78 \mathrm{mM})$.

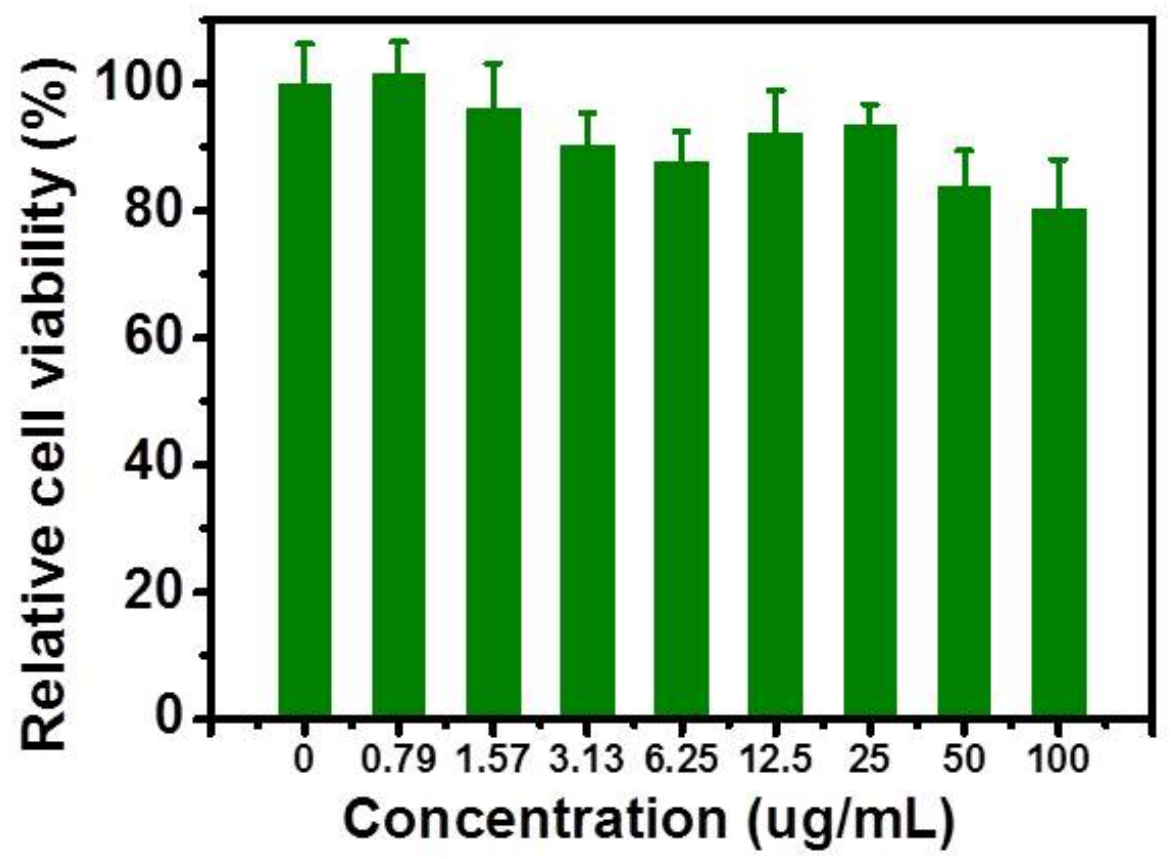

Figure S6. Relative viabilities of 4T1 murine breast cancer cells incubated with MMPF NPs for $24 \mathrm{~h}$, as measured by MTT assay. 


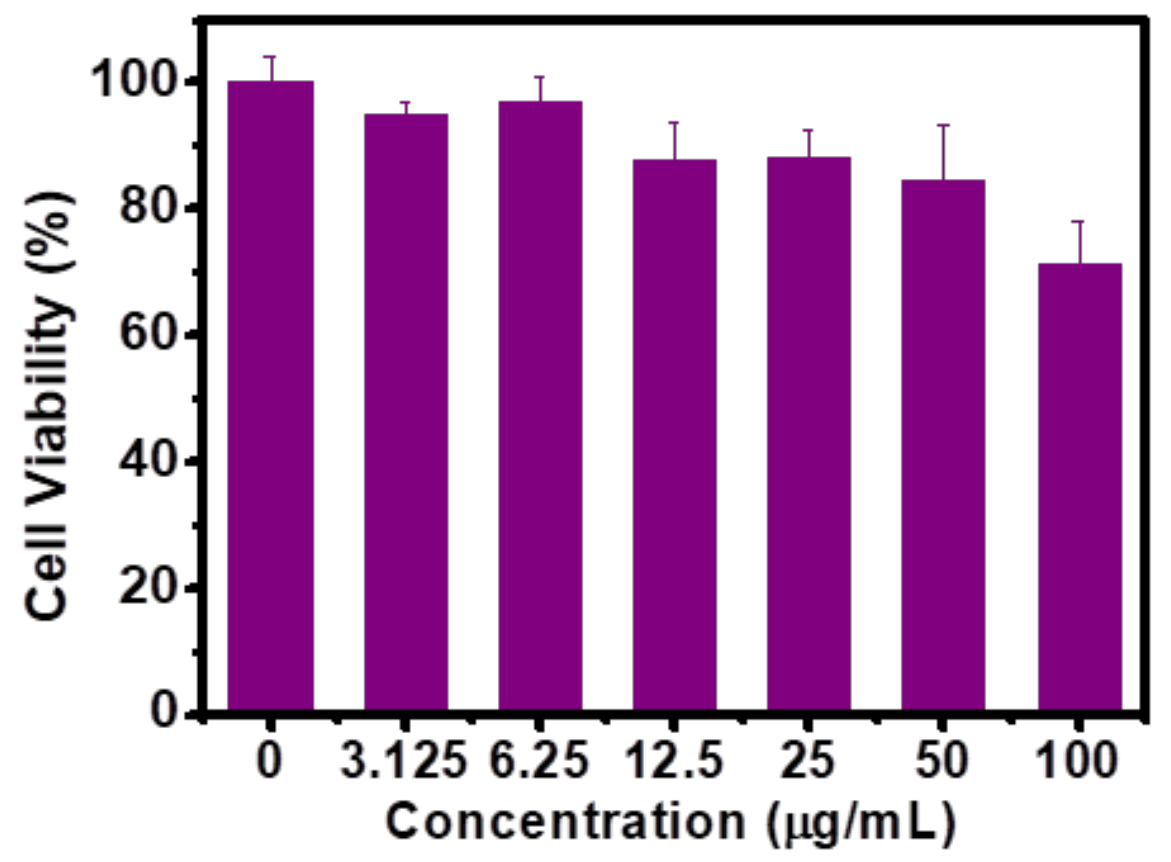

Figure S7. Relative viability of normal human hepatic cell line Lo2 incubated with MMPF NPs for 72 hours, as measured by MTT assay.

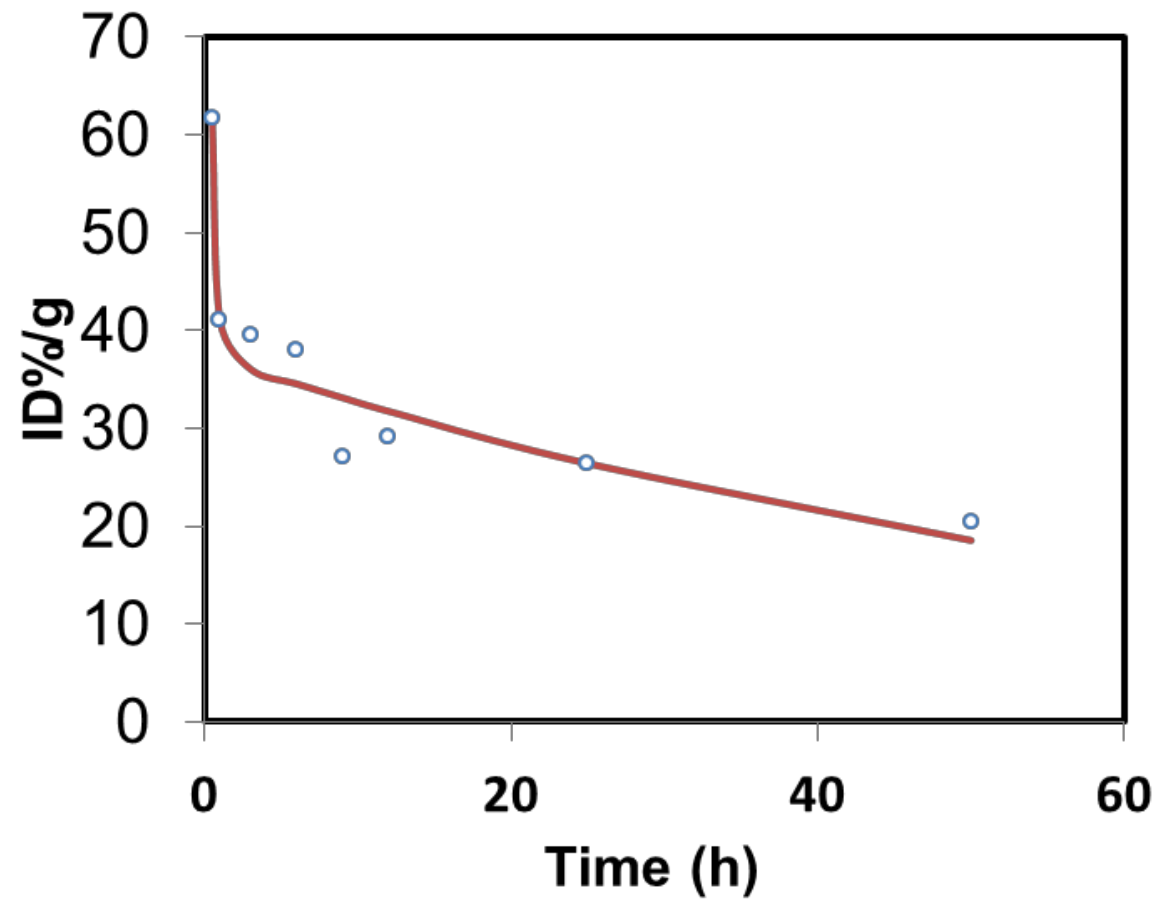

Figure S8. The two-compartment model fitting of the blood circulation profile. The blood samples taken from mice at different time points post i.v. injection of MMPF NPs and the concentration of MMPF NPs was calculated from the MPI signal in blood. 

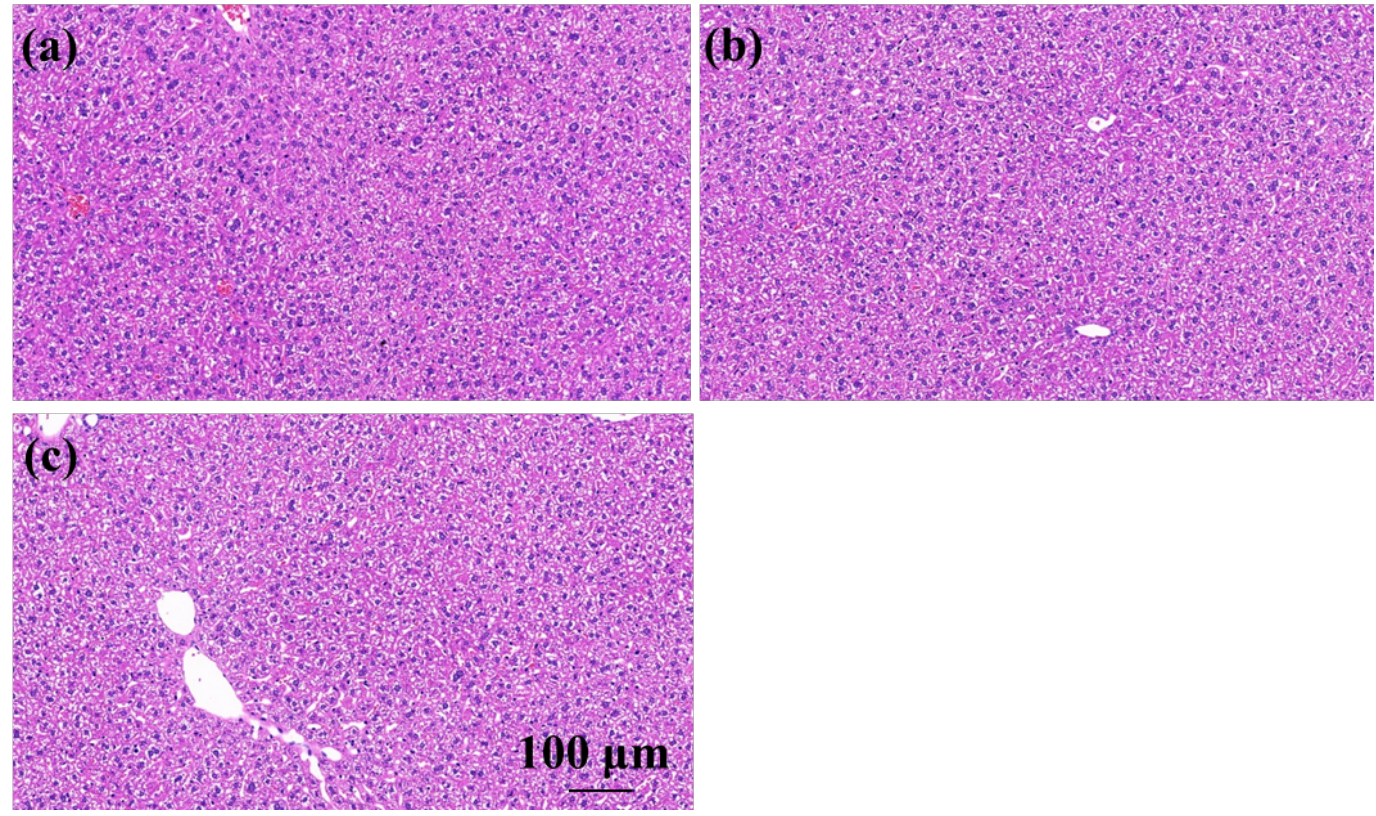

Figure S9. H\&E-stained tissue sections of liver of mice receiving intravenous injection of MMPF NPs (2 mg/kg); (a) Untreated healthy mice, (b) 1st day post injection, and (c) 7th post injection. 
(a)

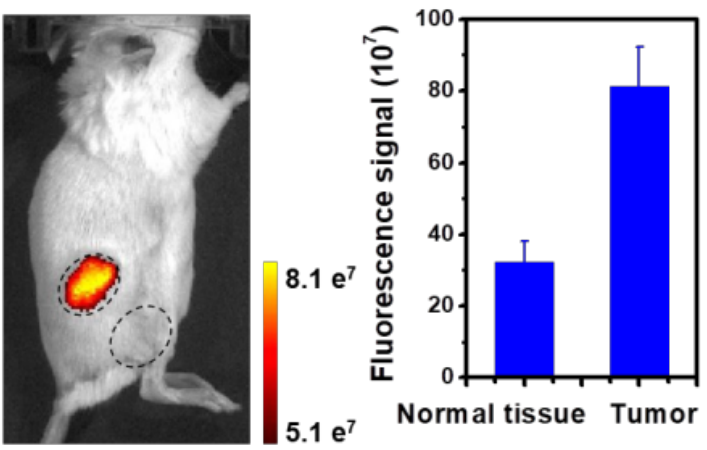

(c)

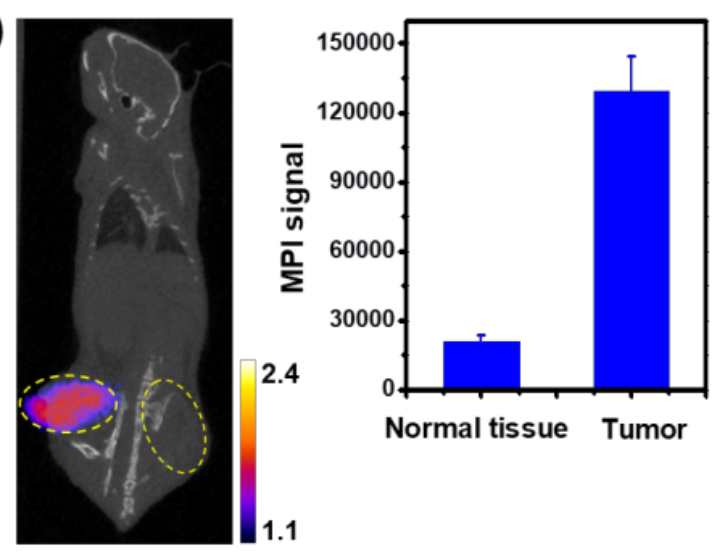

(b)
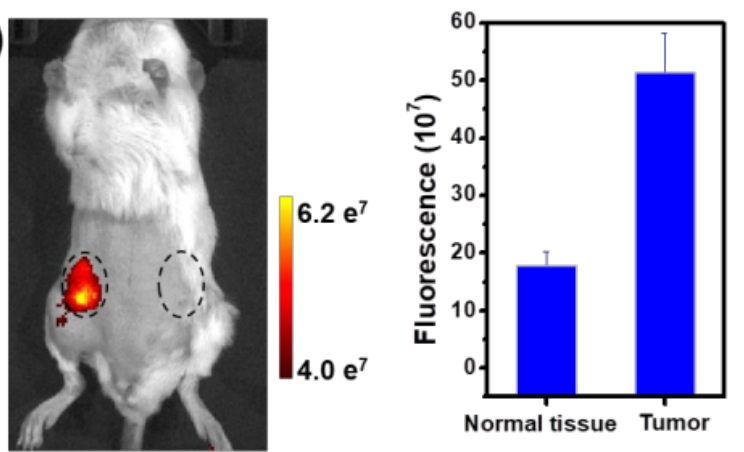

(d)
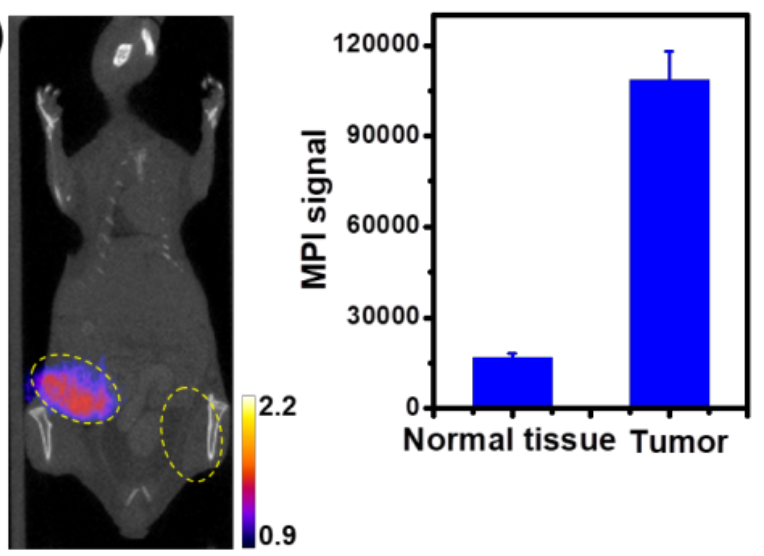

Figure S10. Mice bearing breast cancer 4T1 tumor injected with MMPF NPs ( $2 \mathrm{mg} / \mathrm{kg})$. (a \& b) Fluorescence images of mice at $24 \mathrm{~h}$ post i.v. injection and corresponding quantification of fluorescence signal of tumor and normal tissue: (a) subcutaneous tumor model, and (b) orthotopic tumor model. (c \& d) MPI images of mice at $24 \mathrm{~h}$ post i.v. injection and corresponding quantification of MPI signal of tumor and normal tissue: (c) subcutaneous tumor model, and (d) orthotopic tumor model.

\section{DAPI}

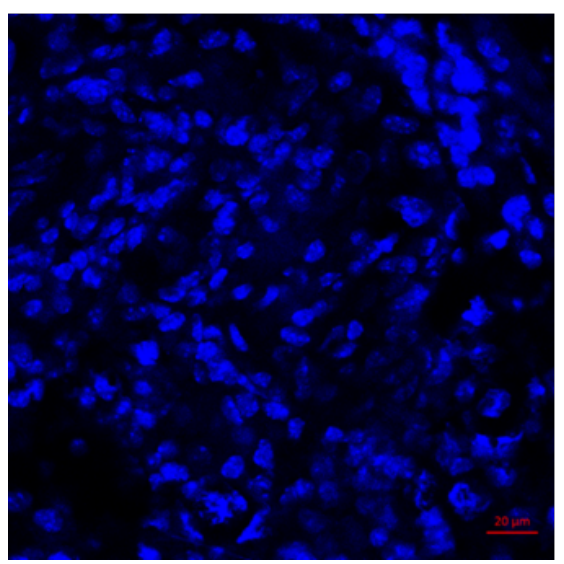

MMPF NPs

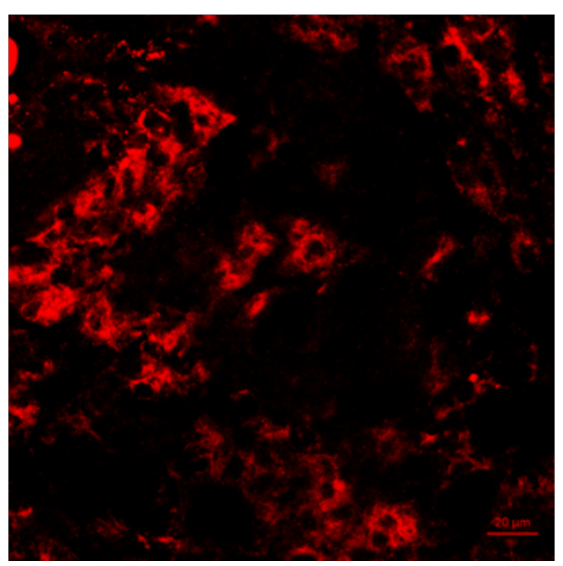

Merge

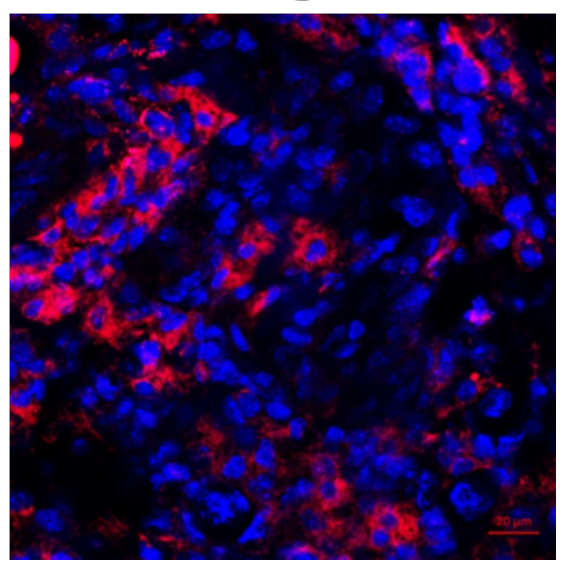


Figure S11. Confocal images of 4T1 tumor slice stained with DAPI. Blue fluorescence indicates nuclei staining and red fluorescence indicates MMPF NPs.
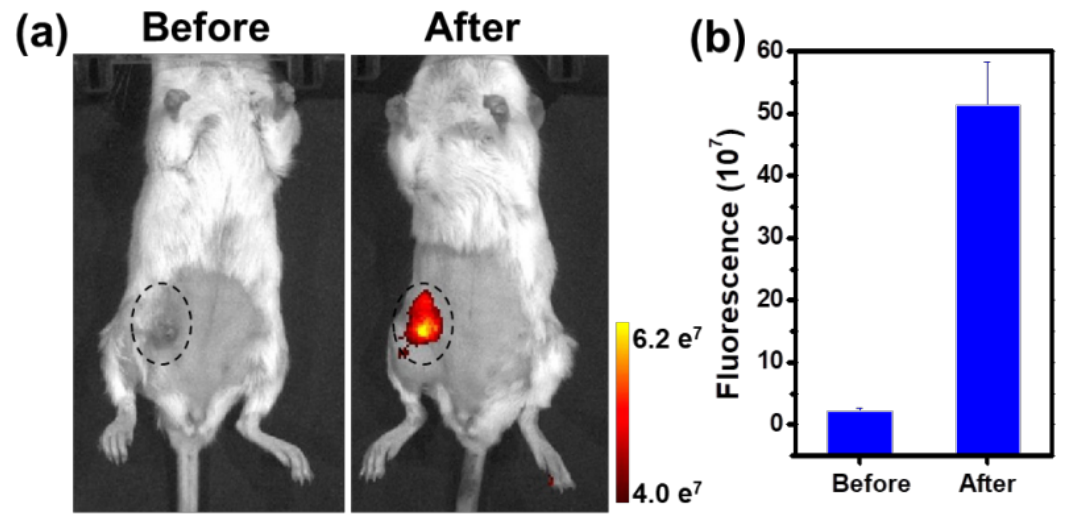

(c)

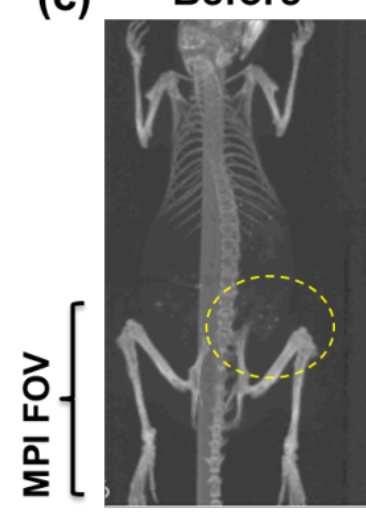

After

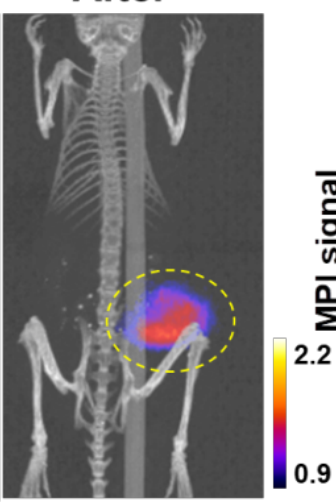

(d)

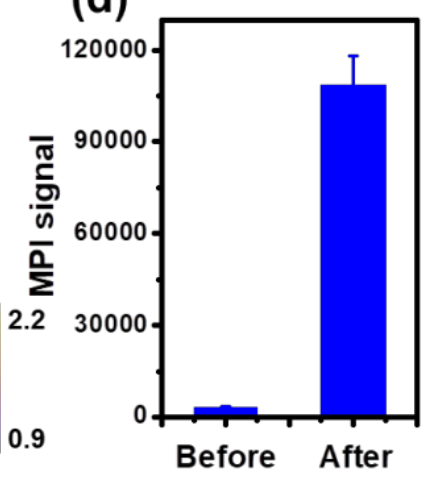

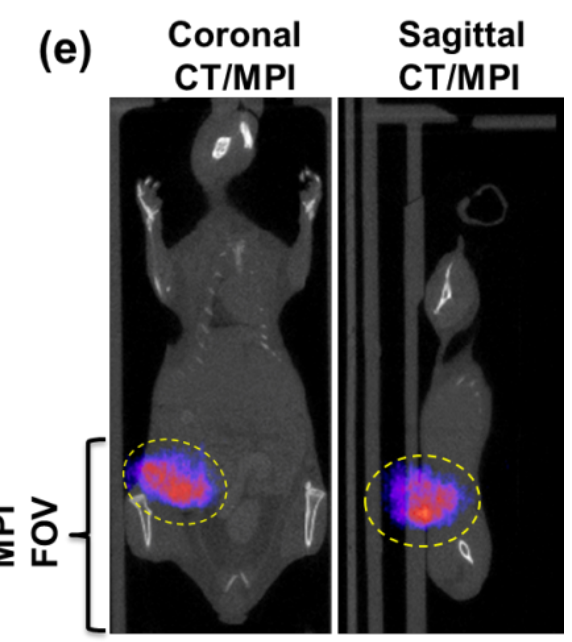

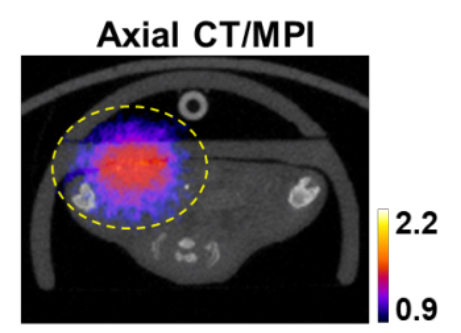

Figure S12. Multimodal images of murine breast cancer 4T1 orthotopic breast cancer tumor before and $24 \mathrm{~h}$ post i.v. injection of MMPF NPs ( $2 \mathrm{mg} / \mathrm{kg}$ ). (a \& b) fluorescence images and corresponding quantification. (c \& d) 3D-MPI/CT images and corresponding quantification with a FOV of $4 \times 4 \times 4 \mathrm{~cm}$. (e) Coronal, Sagittal, Axial MPI/CT images of mice after i.v. injection of MMPF NPs with a FOV of $4 \times 4 \times 4 \mathrm{~cm}$.

Supporting movie I: 3D MPI/CT images of murine breast cancer 4T1 subcutaneous tumor model i.v. injected with MMPF NPs $(2 \mathrm{mg} / \mathrm{kg})$ and imaged at 24 hours post injection with a FOV of $4 \times 4 \times 10 \mathrm{~cm}$. 
Supporting movie II: 3D MPI/CT images of murine breast cancer 4T1 orthotopic breast cancer model i.v. injected with MMPF NPs $(2 \mathrm{mg} / \mathrm{kg})$ and imaged at 24 hours post injection with a FOV of $4 \times 4 \times 10 \mathrm{~cm}$. 